\title{
The Effects of Disease Vulnerability on Preferences for Self-Similar Scent
}

\author{
Naomi K. Muggleton ${ }^{1} \cdot$ Corey L. Fincher ${ }^{1}$ \\ Published online: 4 March 2016 \\ (C) The Author(s) 2016. This article is published with open access at Springerlink.com
}

\begin{abstract}
Humans possess disease avoidance mechanisms, which promote xenophobic attitudes under conditions of perceived vulnerability to disease (PVD). We investigate whether concerns about disease vulnerability influence attraction to olfactory cues of self-similarity. Participants donated a sample of their body odour, then completed a PVD questionnaire (subscales: germ aversion, perceived infectability; Duncan et al. 2009). Told that they were rating strangers' odours, participants rated self, versus non-self, scent donations. Among women, attraction to self-scent was positively predicted by germ aversion (but not perceived infectability); surprisingly, men's ratings of self-scent were negatively associated with germ aversion. Priming with pathogenic cues did not influence scent preferences. This association between germ aversion and odour preference suggests that mere scent exposure can inform the receiver of the immunological similarity between self and sender, which can influence social responses (i.e. attraction to vs. avoidance of scent sender). We discuss these results, as well as implications for the study of intergroup biases.
\end{abstract}

Keywords Behavioural immune system · Disease avoidance . Intergroup bias $\cdot$ Olfactory cues $\cdot$ Individual recognition

The full dataset can be found here: doi:10.17605/OSF.IO/RXGMB

Electronic supplementary material The online version of this article (doi:10.1007/s40806-016-0043-y) contains supplementary material, which is available to authorized users.

Corey L. Fincher

c.fincher@warwick.ac.uk

1 Department of Psychology, University of Warwick, Coventry, UK

\section{Introduction}

\section{The Behavioural Immune System}

Throughout history, the reproductive fitness of individual organisms has been compromised by infectious disease. In response, hosts have evolved defence systems to protect against potential threats. The classical immune system represents several defence mechanisms, such as the cellular- and tissuebased structures, designed to detect and defend against pathogenic organisms, which pose a threat to overall fitness. Despite providing highly specialised protection, mobilisation of the immune system is often costly (e.g. depletion of resources; increased caloric consumption; see Schaller 2011), with physiological responses hindering various mating opportunities (e.g. vomiting, fever, fatigue; Sheldon and Verhulst 1996).

Given these costs, an optimal strategy would be to detect and avoid pathogen contact altogether (see Loehle 1995). The behavioural immune system reflects an additional suite of mechanisms, which promote the avoidance of cues associated with immunological threats (Schaller and Park 2011; Thornhill and Fincher 2014, 2015). Because pathogen transmission is facilitated by group interactions, the behavioural immune system identifies social cues associated with infectious disease or poor health (e.g. rashes, coughs) and promotes avoidance strategies. In this way, costly activation of the classical immune system is minimised.

Research on pathogen avoidance has shown that activation of the behavioural immune system is mediated by an individual's perceived vulnerability to disease (PVD). Specifically, perceived threat of infection is positively correlated with discrimination against individuals categorically associated with poor health, such as the elderly, obese and those with physical disabilities (Duncan and Schaller 2009). 
The behavioural immune system also promotes xenophobia under conditions of pathogen stress (Navarrete et al. 2004; Navarrete and Fessler 2006). Avoidance of foreigners can be considered adaptive, for several reasons. First, contact with foreign outgroups can confer risky exposure to exotic pathogens, to which natives have not acquired antibodies (McNeill 1976; Diamond 1998). Second, communities can protect allies and their dependents, through the provisioning of healthcare, food and protection (Sugiyama 2004), making these ties especially beneficial under conditions of high pathogen stress. The significance of ingroup support is especially pronounced for women, who are more likely than men to care for infants (Trivers 1985; Kenrick et al. 1990). Finally, migrants may engage in social norms (e.g. food preparation, hygiene and sexual practices, medicinal customs) which, while adaptive in their native society, are maladaptive in the present setting (Schaller and Neuberg 2008). Given the threat posed by people who are immunologically distant, attraction to immunologically similar conspecifics is considered adaptive under conditions of pathogen threat.

Despite the functionality of xenophobic beliefs, outgroup interactions provide opportunities for trade or technological advances, and diversification of the gene pool (e.g. Trivers 1985; Hamilton et al. 1990). Further, avoidance strategies can be metabolically and calorically costly. Because of these costs, the behavioural immune system is expected to be engaged flexibly, with pathogen threat determining an individual's social attitudes towards foreigners.

Consistent with this view, research shows that fears of disease infection promote xenophobic attitudes towards foreign (but not familiar) migrant groups (Faulkner et al. 2004; Navarrete and Fessler 2006). This is thought to minimise exposure to exotic pathogens, while amplifying ingroup attraction. Supporting this idea, women in their first trimester report higher levels of ethnocentrism and ingroup bias (Navarrete et al. 2007). Early pregnancy is associated with the suppression of immunological responses, making pathogen avoidance increasingly important. Therefore, the perception of disease vulnerability likely moderates attraction towards the ingroup, while deterring gregariousness towards immunologically distant others.

\section{Detection of Ingroup Through Olfactory Cues}

To date, no research has directly tested what environmental cues facilitate the detection of immunological similarity. In ancestral environments, accurate detection of similar individuals would be a necessary predicator of attraction/avoidance behaviour. For humans, contextual cues such as associative learning, self-inspection and proximity during childhood can provide an approximate estimation of genetic relatedness (Penn and Frommen 2010). More directly, kin recognition can be informed by phenotypic cues from the sender, such as visual, acoustic or olfactory markers, which mark genetic relatedness (Penn and Frommen 2010). To provide meaningful cues, these markers must be both highly variable within a society and significantly correlated with genetic relatedness (Sherman and Holmes 1985; Waldman et al. 1988).

The major histocompatibility complex (MHC) meets both criteria. MHC genes are closely linked with an individual's immune function (Singh 2001) and influence the sender's body odour, thus providing cues for self-identification, kin recognition and inbreeding avoidance (Porter and Moore 1981; Egid and Brown 1989; Isles et al. 2001; Beauchamp and Yamazaki 2003). Individual differences in body odour are associated with variation in MHC genes (Kwak et al. 2010). Due to great diversity among populations, these olfactory cues can notify the receiver of senders' MHC similarity to self (Wedekind et al. 1995) and ethnic ancestry (Marxer-Tobler and Pineda 2012). Humans are also adept at using olfactory cues to match their scent with that of kin (Weisfeld et al. 2003; Lundström et al. 2008). Finally, MHC genes have a central role in pathogen detection and the immune process, making this highly relevant to disease avoidance strategies (Hughes and Hughes 1995; Apanius et al. 1997). Given the evident importance of olfactory cues in kin recognition, it seems highly plausible that the detection of immunological similarity could be mediated through body odour.

\section{The Present Research}

We propose that immunological distance can be measured via olfactory cues. One way to test this is to determine whether those with high chronic disease concern are especially attracted to immunologically similar scent as a way to avoid people who are immunologically distant.

We tested this proposition by investigating whether individual differences in PVD predicted liking for self, versus non-self, body odours. Told that they were rating strangers' odours, participants rated samples of their own scent, which were donated prior to the experiment. The scores were contrasted with participants' ratings of same-sex strangers. Samples were scored for hedonic liking (attractiveness, desirability, pleasantness). We measured disease concern using Duncan et al.'s PVD instrument (Duncan et al. 2009). Prior to scent exposure, participants were also primed with visual cues of infectious disease (pathogen-primed condition) or with images of office equipment (control condition). We investigated whether concern about infectious disease or priming pathogen salience affected individual liking for self/nonself odour samples.

Increased liking for self-similar (vs. dissimilar) scents would simultaneously encourage avoidance of immunologically distant conspecifics and ingroup attraction behaviours and is therefore optimal under conditions of chronic PVD. We predicted that individuals who perceived themselves to 
be vulnerable to infection would display an increased preference for their own scent, relative to the scent of strangers. For self samples, PVD score should be positively associated with attractiveness, desirability and pleasantness; for non-self samples, we anticipate the opposite findings (Hypothesis 1).

Visual primes of potential disease threats have been shown to enhance both immunological and psychological responses, designed to protect individuals from pathogens (Schaller et al. 2010). Primes also induce prejudiced attitudes towards obese people (Park et al. 2007), older adults (Duncan and Schaller 2009) and immigrants (Faulkner et al. 2004). To test whether pathogen priming influences preferences for self-similar scents, we exposed participants to visual depictions of infectious disease. Relative to controls, we hypothesised that individuals in the pathogen-primed condition would display an increased preference for self-scent (i.e. higher attractiveness, pleasantness, desirability; Hypothesis 2).

Finally, we anticipated that the behavioural immune system should be more sensitive in females, arising from the distinctive challenges faced by men and women in ancestral environments. For women, pathogen-mediated attraction to kin confers greater coalitional support for self and dependents. In accordance with this, we predict that kin attraction would be stronger in our female cohort (Hypothesis 3).

To summarise, we investigated whether individuals with high disease concern rate self-similar scents as most pleasing. After testing PVD and inducing temporary disease concern, participants rated samples of self and others' scent for hedonic liking.

\section{Controlling for Confounds}

Disease concern is correlated with measures of the Big Five personality traits (Schaller and Murray 2008; Duncan et al. 2009) and perceived health (Prokop et al. 2010a). We controlled for participants potentially providing polite, rather than truthful, ratings of strangers' scents by using social desirability bias as a covariate (e.g. Crowne and Marlowe 1964; cf. Duncan et al. 2009).

Among women, differences in reported liking of self/nonself scent could reflect menstrual cycle effects. Intrasexual competition is well documented among women (Buss and Dedden 1990; Vaillancourt and Sharma 2011), with aggression greatest during fertility peaks (Durante et al. 2011). Alternatively, women taking hormonal contraceptives, whose cyclic fluctuations are naturally suppressed, are less likely to derogate female competitors (Cobey et al. 2013). Finally, female's responses to olfactory cues are sensitive to fluctuations in the sender's fertility, with hostility most prevalent during peaks in conception risk (Maner and McNulty 2013). To control for possible female derogation of non-self scents, we used rater fertility as an additional covariate for scent liking.

\section{Method}

\section{Participants}

Forty-seven participants (female $=29$ ) were recruited through the University of Warwick Research Participation System. The project required that participants were healthy (i.e. not suffering from persistent health conditions; have not taken prescriptive drugs within the past month), non-smokers and reporting a functioning sense of smell. All participants were financially reimbursed for their time.

In sum, nine participants were excluded from testing, as a consequence of menstrual cycle abnormalities (three women) or voluntary withdrawal. In total, 22 women (age $M=24.70$; $S D=5.54)$ and 16 men $(M=24.94 ; S D=3.65)$ were included for data analysis. Self-reports showed that $37 \%$ were East Asian, $26 \%$ White, $18 \%$ West Asian, $5 \%$ Arabic, $2 \%$ African, and $10 \%$ reported their ethnicity as mixed/other.

\section{Materials}

For body odour collection, participants received a sterilised absorbent gauze $(5 \mathrm{~cm} \times 5 \mathrm{~cm})$, microsurgical tape $(1.25 \mathrm{~cm} \times 5 \mathrm{~m})$, non-perfumed shower gel (brand: Simple) and a coded bag for depositing the donation. During the scent rating task, samples were presented in conical flasks $(500 \mathrm{ml})$, with an attached foil cap. Between use, flasks were cleaned using a laboratory grade detergent.

\section{Design}

In a mixed-factorial design, PVD score (subscales: Germ Aversion, Perceived Infectability), priming (Pathogen, Control) and scent (Self, Non-Self) were the independent variables. PVD score and scent were both within-subject factors, and priming was a between-subject factor. Participants were randomly assigned to priming conditions. The dependent variables were ratings of attractiveness, desirability and pleasantness. Due to the directional nature of our hypotheses, all tests reported in the results section were one-tailed and the significance level was $\alpha=0.05$.

\section{Procedure}

Participants attended three sessions. The first meeting consisted of collecting menstrual cycle information (female participants) and providing instruction for scent donation, which participants administered at home. Participants then collected their odour sample and delivered it to the laboratory (meeting 2). The third meeting included the PVD questionnaire, pathogen priming and the scent rating task. 


\section{Meeting 1-Participant Interviews}

To prepare for scent collection, participants received instruction on pad application. For $24 \mathrm{~h}$ prior to collection, participants refrained from the following: eating pungent foods (garlic, curry, chilli, strong herbs and spices, onion, cabbage, blue cheese, fermented milk products, fish); smoking, consuming alcohol or recreational drugs; sexual intercourse or sharing a bed; and perfumed moisturisers, shower gels, antiperspirants or deodorants. Prior to sampling, participants were instructed to use the non-scented shower gel provided and affixed the gauze pad to the axillary (i.e. underarm) region using surgical tape. To minimise side-related effects (Ferdenzi et al. 2009), participants applied a pad to each axilla.

Female participants completed a questionnaire about their menstrual cycle (adapted from Durante et al. 2014). Women verified the date of their previous menses and mean cycle length and self-reported whether their cycle was typically 'regular' or 'irregular'. Participants used mobile phone calendars for assistance. To control for any potential hormonal effects on odour perception (Wedekind et al. 1995; Roberts et al. 2008), all participants reported that they had not been pregnant or taking hormonal contraceptives, for the 3 months prior to the study. Finally, participants were instructed to email the female researcher on the first day of their next menses, to maximise accuracy of estimates.

\section{Meeting 2-Collection of Odour Samples}

To minimise menstrual effects on hedonic preferences (Havlíček et al. 2006), female scent collection was scheduled to ensure that all women were luteal (i.e. post-ovulation). Subsequent reports of women's menses confirmed that cycle estimates were accurate for all participants. Male scent collection was scheduled at the earliest convenience for experimenter and participant.

On the scheduled day, participants would apply the pad in the evening, and remove upon waking. Pads were worn for $12 \mathrm{~h}$, to minimise the risk of floor effects (see Havlíček et al. 2011). The following morning, pads were transferred to the pre-coded bag (specifying left or right axilla) and handdelivered by 10 a.m. Upon delivery, all participants confirmed that they had avoided prohibited activities and worn the pad for $12 \mathrm{~h}$. Samples were stored in a freezer, an established method to preserve body odour for over 6 months (Lenochová et al. 2009).

\section{Meeting 3-Scent Exposure Procedure}

The third meeting comprised (i) questionnaires; (ii) pathogen priming and (iii) exposure to scent samples. Questionnaires collected various personal data (e.g. age, ethnicity, health status, social desirability bias, personality, sexual orientation, social dominance orientation (SDO: one's preference for inequality between social groups; Pratto et al. 1994)). Disease concern was measured using the PVD scale (Duncan et al. 2009), details of which can be found below. For the pathogen priming task, participants were presented with 10 images, displayed for $6 \mathrm{~s}$, with each image being displayed twice. In total, the priming slideshow took $2 \mathrm{~min}$ to administer.

Scent exposure followed immediately after priming. The experiment consisted of two trials, each containing eight participants' donations (one belonging to the scent rater; seven from randomly selected others). Hence, participants rated the samples of eight donors, twice. Sampling order was randomised across blocks. Participants were falsely told that all scents were collected from donors $24 \mathrm{~h}$ prior. This meant that participants were not aware of their scent within the set.

Participants were instructed to remove the foil cap, rate the scent, and take a 15-s break before the next scent exposure. Based on previous findings (Ferdenzi et al. 2009), participants took a 5-min break between trials to avoid olfactory fatigue. During the debrief, participants were asked whether they suspected that they had rated their own scent. Two participants had correctly guessed; their responses did not significantly differ from other participants.

\section{Psychological Instruments}

\section{Measurement of Chronic Disease Concern}

To measure individual differences in chronic disease concern, participants completed a 15-item Perceived Vulnerability to Disease questionnaire (Duncan et al. 2009), a proven psychological instrument that has been used in several investigations (e.g. Park et al. 2007; Wu and Chang 2012). The questionnaire measures two internally consistent subscales; an eight-item Germ Aversion (GA) subscale measures emotional discomfort in situations where potential pathogen exposure is high, and a seven-item Perceived Infectability (PI) subscale measures belief about one's resistance to infection. Responses were measured on a 7-point scale $(1=$ strongly disagree and $7=$ strongly agree).

\section{Temporarily Induced Vulnerability to Disease}

Participants in the pathogen condition were presented with a slideshow of individuals displaying visible signs of infectious disease (e.g. sneezing, skin lesions, pox; adapted from Schaller et al. 2010). In the control condition, individuals watched a slideshow of office supplies (e.g. paper clips, rubber bands, staplers). Images were sourced from online directories. 


\section{Rating Scale}

As with previous studies, participants rated the Attractiveness and Pleasantness of samples (Wedekind et al. 1995; Havlíček et al. 2006). We included a measure of Desirability, which asked: "how would you rate the individual's level of desirability as a partner to the opposite sex?" (adapted from Edlund and Sagarin 2014). Three measures of scent liking allow for differentiation between intergroup bias and intrasexual competition. Intrasexual competition would anticipate differences between Self/Non-Self ratings along the attractiveness and desirability dimensions, but not for pleasantness.

Samples were rated on a Likert-type scale: Attractiveness, -3 (very unattractive) to 3 (very attractive), Desirability, -3 (very undesirable) to 3 (very desirable), and Pleasantness, -3 (very unpleasant) to 3 (very pleasant). Participants were instructed that an 'average' sample would equate to 0 . Ratings were provided verbally and recorded by the researcher.

\section{Data Treatment}

\section{Calculation of Hedonic Ratings}

During scent exposure, each participant rated two samples (left and right side) from eight participants. We calculated the mean rating that each participant gave to each scent donor for Attractiveness, Desirability and Pleasantness. This produced one set of Self scores, plus seven sets of Non-Self scores. Non-Self scores were subsequently averaged, giving us three scores on Self samples and three scores on Non-Self samples.

Across sex, the correlation between Attractiveness, Desirability and Pleasantness ranged from 0.83 to 0.92 , all $p$ values $<.001$, signalling that intrasexual competition did not account for differences in rating. Hence, these subscales were summed, to provide a perceived goodness-of-sample rating (Self and Non-Self score).

To investigate the extent to which participants preferred their own scent over that of strangers, we measured the relative difference between each participants' Self and Non-Self rating. This Self Preference Index (SPI) was calculated by subtracting participants' NonSelf sample score from their Self score. A positive value would indicate a preference for Self, relative to NonSelf samples.

In summary, our analysis compared participants' SPI, plus its subscales (Self and Non-Self ratings). Analysis of specific sub-components (Attractiveness, Desirability, Pleasantness) yielded highly similar findings.

\section{PVD Subscales}

For the PVD questionnaire, the internal consistency between all 15 items was acceptable, Cronbach's alpha $=.80$. However, following the authors' recommendations (see Duncan et al. 2009), we treated GA and PI as separate subscales for the purposes of our analysis. For the eight-item, GA scale, Cronbach's alpha $=.78$; for the seven-item, PI scale, Cronbach's alpha $=.86$. We observed no correlation between GA and PI scores, $(r=.18, p=.14, n=35)$, indicating that both subscales should be analysed separately. Preliminary analysis revealed that PI was not associated with SPI, or its subscales (Table S1, Online Resource 1). This is consistent with the previous finding that GA, but not PI, can predict intergroup biases (Faulkner et al. 2004). In contrast, PI predicts reactions to cues of immunodeficiency (e.g. attitudes toward the elderly, Duncan and Schaller 2009; or facial symmetry, Young et al. 2011). Given this, we followed the guidance of previous studies (e.g. Huang et al. 2011; Murray et al. 2013) and omitted PI from all subsequent analysis; we instead focus on GA as a predictor of scent preferences.

\section{Menstrual Cycle}

Data obtained from questionnaires were used to estimate women's cycle length in days $(M=30.48 ; S D=3.47)$ and menses onset. Participants emailed the researcher on the first day of their next menses, to maximise accuracy of estimates. To ensure that all women were in the luteal phase at scent collection, we used the backward counting method, which assumes that ovulation occurs 14 days prior to menses (Jöchle 1973). In a recent simulation of 58,000 ovulatory cycles, this method was shown to be a valid measure of women's fertility status (Gangestad et al. 2015). To further maximise accuracy, a 2-day buffer was factored in, when scent should not be collected. For instance, for a woman with a cycle length of 30 days (ovulation= day 16; luteal window = days 17-29), scent collection would be scheduled between days 18 and 28 . Email responses indicated that all estimates of the luteal window were accurate. Finally, cycle phase at meeting 3 (follicular (i.e. pre-ovulation), luteal) was calculated for further analysis.

\section{Risk of Conception}

Using reports from medical literature (Wilcox et al. 2001), we calculated female participants' probability of pregnancy from a single act of intercourse. Values were produced by calculating women's cycle day at meeting 3 and reflected whether their cycles were regular or irregular. Values ranged from 0.00 and $0.094(M=0.023 ; S D=0.030)$. Together with cycle phase estimates, we assess whether fertility promotes derogation of others' scent. 


\section{Results}

\section{Chronic Disease Concern}

Are preferences for self-scent predicted by disease concern? Table 1 presents a multiple regression analysis of SPI and its subscales: Self and Non-Self scores. The model includes Sex and GA as predictors, plus its interaction.

\section{$S P I$}

Do chronic disease concerns influence individuals' relative preference for their own scent over that of strangers? We found a significant main effect for Sex and GA (Table 1). The model also revealed a significant interaction between GA and Sex. Regression slope tests revealed that for women, GA scores positively predicted SPI, $\beta=0.51, t(20)=2.67$, $p=0.007$ (Fig. 1a; see Table S2, Online Resource 1). For men, we observed the opposite effect, though this was not significant, $\beta=-0.37, t(20)=-1.51, p=0.08$. This indicates that women's attraction to self, relative to strangers, increased as a function of GA.

So far, we have asked whether GA predicts SPI. However, SPI is composed of two subscales: Self and Non-Self scent ratings. As such, SPI alone cannot reveal whether GA moderates preference for self-similar scents or derogation of strangers' scents. The next two sections aim to address this, by investigating participants' preference for Self and Non-Self scents in isolation.

\section{Ratings of Self Scent}

Analysis of Self Scent scores revealed significant main effects for Sex and GA, $p$ values $<.04$ (Table 1). The model also revealed a significant interaction between Sex and GA. Further analysis revealed that, for women, GA scores positively predicted liking for Self scent, $\beta=0.41, t(20)=2.01$, $p=0.03$ (Fig. 1b). For men, GA scores negatively predicted Self scent scores, $\beta=-0.44, t(14)=-1.86, p=0.04$.
These findings suggest that GA could promote attraction to self scent among women, but avoidance behaviours among men.

\section{Ratings of Non-Self Scent}

Next, we asked whether men and women differentially avoid strangers' scents, as a function of chronic disease concern. We observed no main effect for Sex or GA (Table 1; Fig. 1c); the interactions did not yield significant findings. This indicates that disease concern did not motivate derogation of others' scents.

Further regression analyses ruled out alternative explanations, such as SDO, social network intensity, personality, social desirability score, perceived health rating, and infection frequency or recency (for full regression results, see Table S3, Online Resource 1).

\section{Temporary Disease Concern}

To explore the effect of pathogen priming on SPI, we conducted a 2 (rater's sex) by 2 (condition: pathogen priming or control) factorial ANOVA. We found no main effect for participant condition, $F(1,34)=0.53, p=0.24$, or Sex, $F(1,34)=0.11$, $p=0.37$. The interaction between Sex and condition was not significant, $F(1,34)=0.00, p=0.49$. Priming did not increase participants' relative preference for their own scent over that of strangers (Fig. 2; see Table S4 (Online Resource 1) for means and SDs).

As in the previous section, we extended our analysis to both SPI subscales. We found no evidence of priming on Self ratings, $F(1,34)=0.72, p=0.20$, or for Non-Self ratings, $F(1,34)=0.02, p=0.44$. No interaction occurred between Sex and condition for Self ratings, $F(1,34)=0.14, p=0.36$, or Non-Self ratings, $F(1,34)=0.56, p=0.28$.

\section{Female Specific Measurements}

To account for intrasexual competition, we asked whether participants' fertility levels at scent exposure predicted

Table 1 Multiple regression for scent ratings as a function of GA and Sex

\begin{tabular}{|c|c|c|c|c|c|c|c|c|c|c|c|c|c|c|c|}
\hline \multirow[t]{3}{*}{ Explanatory variable } & \multicolumn{15}{|c|}{ Dependent variables } \\
\hline & \multicolumn{5}{|l|}{ SPI } & \multicolumn{5}{|l|}{ Self } & \multicolumn{5}{|c|}{ Non-Self } \\
\hline & $B$ & s.e. & $\beta$ & $p$ & $R^{2}$ & $B$ & s.e. & $\beta$ & $p$ & $R^{2}$ & $B$ & s.e. & $\beta$ & $p$ & $R^{2}$ \\
\hline Sex & 7.14 & 1.84 & 1.15 & $<.01$ & & 4.95 & 1.80 & 0.79 & .04 & & -2.20 & 1.47 & -0.63 & 0.07 & \\
\hline GA & 1.47 & 2.71 & 0.55 & $<.01$ & & 1.03 & 2.66 & 0.38 & .03 & & -0.44 & 0.28 & -0.29 & 0.07 & \\
\hline \multirow[t]{3}{*}{ Sex $\times$ GA } & -2.49 & 0.90 & -1.15 & $<.01$ & & -2.37 & 0.52 & -1.10 & $<.01$ & & 0.12 & 0.48 & 0.10 & 0.40 & \\
\hline & & & & & 0.22 & & & & & 0.26 & & & & & 0.27 \\
\hline & \multicolumn{5}{|c|}{$F(3,34)=3.28, p=.02$} & \multicolumn{5}{|c|}{$F(3,34)=3.90, p<.01$} & \multicolumn{4}{|c|}{$F(3,34)=4.23, p<.01$} & \\
\hline
\end{tabular}


(a) SPI

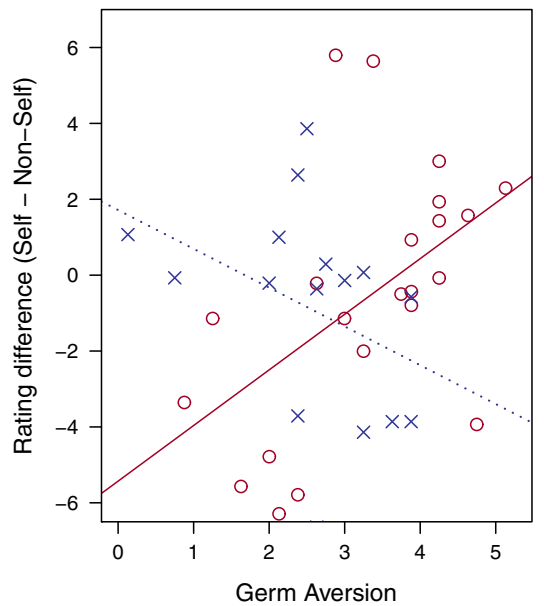

(b) Self scent

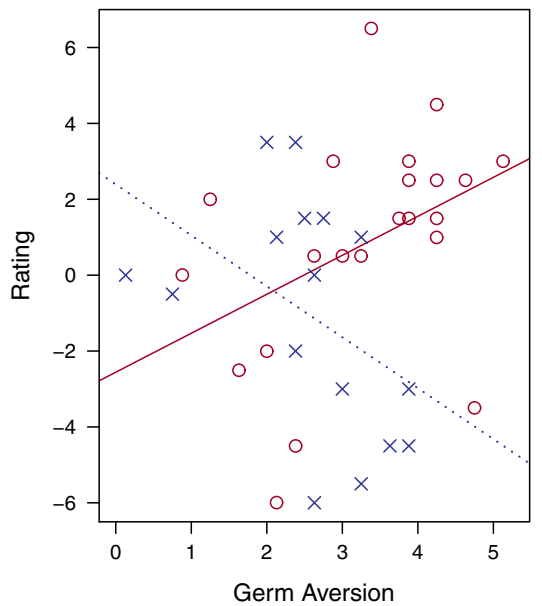

(c) Non-Self scent

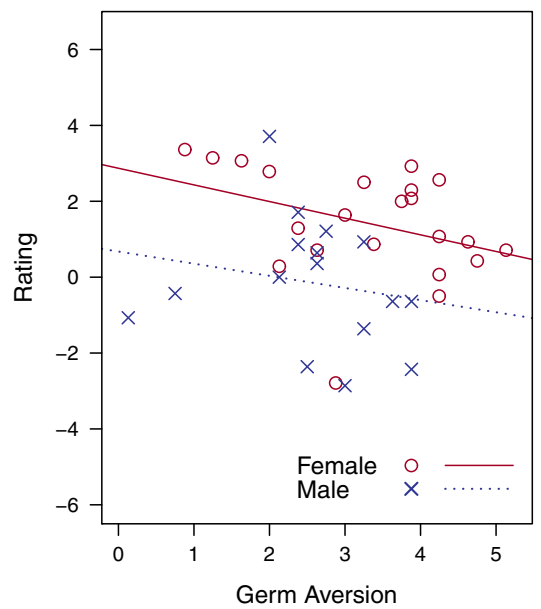

Fig. 1 Mean ratings of scent samples as a function of GA for a SPI, b participants' ratings of own scent and c participants' ratings of others' scent

hedonic ratings. A one-way ANOVA found no significant effect for cycle phase (follicular; luteal) and ratings for Self, $F(1,20)=3.30, p=0.08$, or Non-Self samples, $F(1,20)=0.12$, $p=0.73$ (for means and SDs, see Table S5, Online Resource 1). Regression analysis revealed that raters' likelihood of conception did not predict Self, $\beta=0.10, t(20)=0.43, p=0.33$, or Non-Self ratings, $\beta=-0.05, t(20)=-0.22, p=0.42$. The null effects indicate that our findings are not a consequence of female intrasexual competition.

\section{Discussion}

\section{Olfactory-Mediated Ingroup Attraction Among Women}

Our first hypothesis predicted that women's self-scent preference would increase as a function of chronic pathogen concern. Indeed, we find that preference for one's own scent was predicted by chronic disease concern, indicating that disease avoidance mechanisms are sensitive to olfactory cues of immunological similarity. These findings are consistent with the 'elevated ethnocentrism' hypothesis of disease avoidance (Navarrete and Fessler 2006; Navarrete et al. 2007), which anticipates a heightened preference for self-similar scents, under conditions of disease vulnerability.

Further analysis of the SPI revealed that this effect was driven by attraction to self, and not avoidance of non-self scents. Although Non-Self ratings were negatively predicted by GA, this finding was not significant. Further analysis revealed that, in addition to negatively predicting Non-Self scores, GA was negatively associated with all subscales of hedonic ratings (Attractiveness, Pleasantness, $p$ values $<.08$; Desirability, $p<.05$; see Table S2, Online Resource 1). The null finding was particularly relevant to our prediction that disease concern promotes outgroup avoidance (cf. Faulkner et al. 2004). Prompted by this, we conducted a post hoc (a) SPI

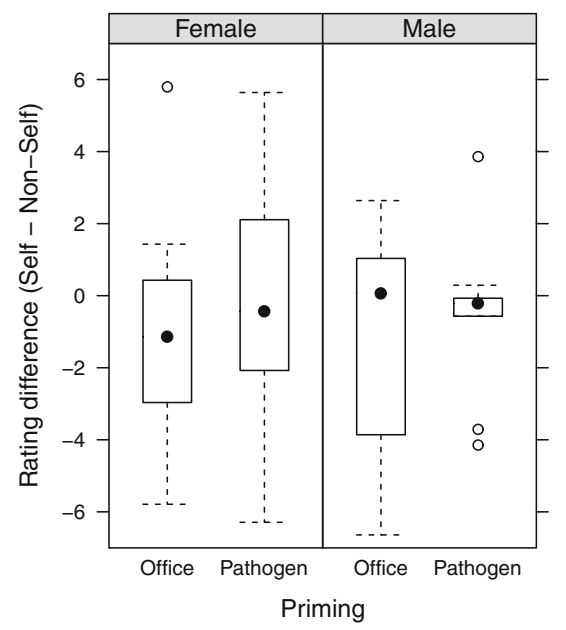

(b) Self scent

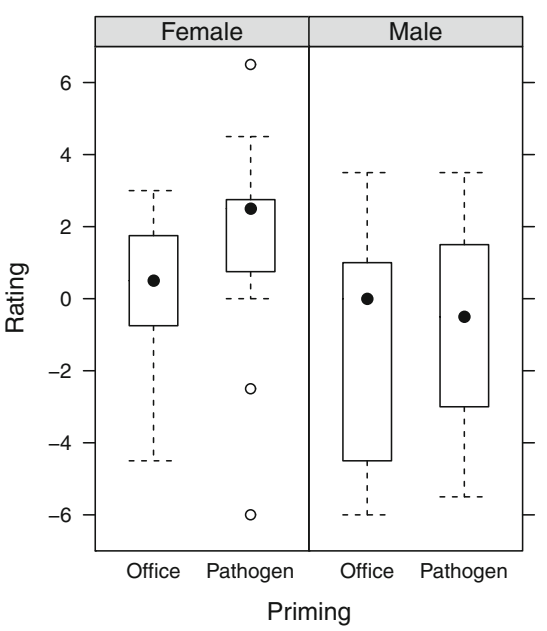

(c) Non-Self scent

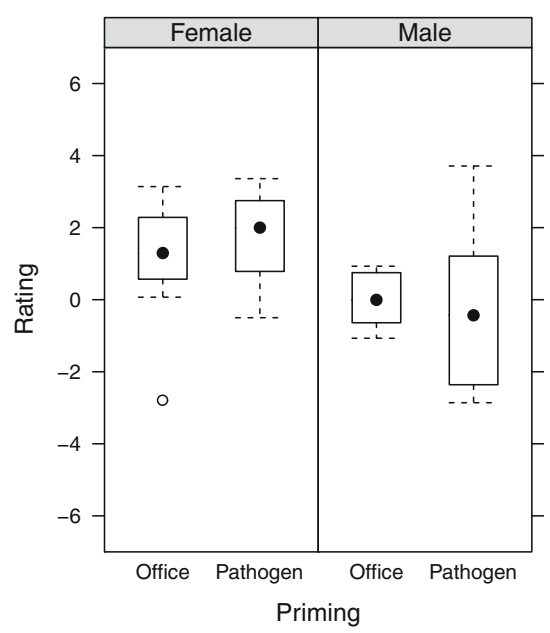

Fig. 2 Mean ratings of scent samples split by Sex and priming condition for a SPI, b Self and $\mathbf{c}$ Non-Self scores 
analysis of our statistical power, using $\mathrm{G}^{*}$ Power (Faul et al. 2007). While the observed power of the Self multiple regression analysis (DV: GA score) was .52, the Non-Self multiple regression yielded a power of less than .40 . To obtain the recommended statistical power $(1-\beta)$ of .80 (Cohen 1988), at $\alpha=.05$, our experiment would require 57 female participants. Given our modest sample $(N=22)$, we cannot reject the possibility that a small effect of GA was present in NonSelf ratings. Such an effect would be consistent with the xenophobic model of disease avoidance (Faulkner et al. 2004), which predicts that GA should promote non-self disliking. Further research is needed to clarify this null finding.

\section{Germ Aversion Induces Kin Avoidance Among Males?}

Our third hypothesis proposed that the effect of disease avoidance mechanisms on self-scent ratings would differ between sexes. Indeed, we observed that GA differentially affected SPI among men and women. As with women, this effect was driven by differences in self attraction, rather than differences in non-self preference. However, our finding that male Self ratings are negatively predicted by GA is somewhat surprising. This finding was robust, and post hoc analysis shows a negative association between Self rating and each hedonic subscale (all $t$ values $<-1.55$; Attractiveness, Desirability; $p$ values $<.036$; Pleasantness, $p=.07$; see Table S2, Online Resource 1). Taken together, these findings indicate that, for men, germ aversion induces ingroup avoidance.

Although it is unclear why men's scent-based preferences should differ from that of women, the significant and robust findings point to marked contrasts between the sexes. Indeed, this pattern may reflect sex differences in responding to pathogen exposure. Prior research has demonstrated a tendency for sick individuals to withdraw socially from kin. When unwell or run down, humans typically retreat from the ingroup, thus minimising the risk of infecting healthy individuals (Loehle 1995). Given that GA is positively associated with geographical levels of pathogen transmission (Prokop et al. 2010b), we might anticipate that individuals experiencing higher levels of GA are increasingly likely to be carriers of infectious disease. From an inclusive fitness perspective (Gardner and West 2014), an adaptive response could be to socially withdraw until threat of transmission has abated.

As we have seen, women are more likely than men to care for infants, making attraction to kin an adaptive response to disease threat, for both mother and child. Further, in ancestral environments, females may not have the luxury of retreating from dependent offspring. For men, we speculate that a tradeoff between kin- and self-protection can occur, such that the ancestral male eschews support, to protect close kin and other ingroup members from infection. Given that MHC genes are a key mediator of body odour, it seems plausible that such cues are carried through olfactory signals. These hypotheses are highly speculative, and further research is needed.

\section{Priming Does Not Affect Scent Preference}

Counter to our second hypothesis, we found that transient threats of disease primed by pathogen cues did not influence scent ratings. This is somewhat surprising, given previous reports that pathogen priming triggers the behavioural immune system (e.g. visual primes of bacteria and germs; Faulkner et al. 2004; Park et al. 2007). There are two possible accounts for these results. First, the null finding could indicate that ratings of self-scent are exclusively influenced by individual differences in chronic disease concern, and not short-term disease primes. Alternatively, these findings are compatible with an emerging body of literature which questions the validity and replicability of priming studies (e.g. Pashler et al. 2012; Newell and Shanks 2014a, b; Shariff et al. 2015).

Recent criticisms have questioned the assumption that fleeting and transient contextual cues can automatically initiate a wide range of behavioural changes (see Newell and Shanks 2014a). Failures to replicate priming effects have been found within the domain of mate-related decision making (Shanks et al. 2015), religiosity (Gomes and McCullough 2015; Shariff et al. 2015), honesty cues (Pashler et al. 2013) and goal achievement (Harris et al. 2012). Investigations into these failed replications have found evidence of both $p$ hacking and publication biases (Gomes and McCullough 2015; meta-analytic evidence: Shanks et al. 2015; Shariff et al. 2015). Within the context of this research, it remains unclear whether visual primes of pathogen stress were sufficiently stable to endure the length of testing. As such, we cannot conclude whether the null finding is specific to the domain of scent preference or indicative of wider methodological issues associated with priming.

\section{Limitations and Future Research}

We provide speculative support for our hypothesis that PVD promotes ingroup attraction, via olfactory cues. Yet, counter to our prediction, chronic disease concern did not predict negative ratings of others' scent. Low statistical power may account for the null finding. Yet, readers will note that our categorisation of 'non-self' is not akin to 'outgroup'. Indeed, given the localised population of the target group, plus similarities in age and educational attainment, our sample cannot be comfortably partitioned along intergroup lines. To complicate matters further, research has shown that xenophobic attitudes towards foreigners dissipate when individuals are from familiar migrant groups (Faulkner et al. 2004).

Ideally, this research would have allowed for the collection of odour sample from non-familiar ethnic outgroups (Faulkner et al. 2004). At a more localised level, future research might 
incorporate genetic information, to test whether the observed preference for self-scent is driven by attraction to self-similar genes. Prior research indicates MHC-associative preferences during social cooperation tasks, with olfactory cues informing kin recognition and attraction/avoidance behaviours (for a review, see Havlíček and Roberts 2009). Genetic testing of participants would allow for more comprehensive analysis and greater generalisability of findings.

\section{Concluding Remarks}

In summary, we provide the first direct evidence that scentbased preferences are influenced by perceptions of disease threat. Women with high levels of germ aversion display a preference for self-similar scents; in men, germ aversion adversely affects ratings of self-scent. This means that, in addition to demonstrating that the behavioural immune system mediates scent preferences, we show that these mechanisms are differentially activated between the sexes. Taken together, this suggests that mere scent exposure can inform the receiver of similarity between self and sender, which can influence social response (i.e. attraction vs. avoidance). These findings complement previous research documenting the role of disease avoidance mechanisms as contributors to ingroup attraction.

The finding that the behavioural immune system differentially responds to self and non-self scents, as a function of pathogen stress, would have been adaptive in ancestral ecologies, and supports the claim that scent-based cues aid identification of immunologically distant others, who may carry novel pathogens. Our findings provide speculative evidence that the behavioural immune system mediates intergroup biases, via olfactory channels.

Open Access This article is distributed under the terms of the Creative Commons Attribution 4.0 International License (http:// creativecommons.org/licenses/by/4.0/), which permits unrestricted use, distribution, and reproduction in any medium, provided you give appropriate credit to the original author(s) and the source, provide a link to the Creative Commons license, and indicate if changes were made.

\section{References}

Apanius, V., Penn, D., Slev, P. R., Ruff, L. R., \& Potts, W. K. (1997). The nature of selection on the major histocompatibility complex. Critical Reviews in Immunology, 17(2), 179-224.

Beauchamp, G. K., \& Yamazaki, K. (2003). Chemical signalling in mice. Biochemical Society Transactions, 31(1), 147-151.

Buss, D. M., \& Dedden, L. A. (1990). Derogation of competitors. Journal of Social and Personal Relationships, 7(3), 395-422.

Cobey, K. D., Klipping, C., \& Buunk, A. P. (2013). Hormonal contraceptive use lowers female intrasexual competition in pair-bonded women. Evolution and Human Behavior, 34(4), 294-298.

Cohen, J. (1988). Statistical power analysis for the behavioral sciences (2nd ed.). Hilsdale, NJ: Erlbaum.
Crowne, D. P., \& Marlowe, D. (1964). The approval motive: studies in evaluative dependence. New York, NY: Wiley.

Diamond, J. (1998). Guns, germs and steel: the fates of human societies. New York, NY: W. W. Norton and Company.

Duncan, L. A., \& Schaller, M. (2009). Prejudicial attitudes toward older adults may be exaggerated when people feel vulnerable to infectious disease: evidence and implications. Analyses of Social Issues and Public Policy, 9(1), 97-115.

Duncan, L. A., Schaller, M., \& Park, J. H. (2009). Perceived vulnerability to disease: development and validation of a 15 -item self-report instrument. Personality and Individual Differences, 47(6), 541-546.

Durante, K. M., Griskevicius, V., Hill, S. E., Perilloux, C., \& Li, N. P. (2011). Ovulation, female competition, and product choice: hormonal influences on consumer behavior. Journal of Consumer Research, 37(6), 921-934.

Durante, K. M., Griskevicius, V., Cantu, S. M., \& Simpson, J. A. (2014). Money, status, and the ovulatory cycle. Journal of Marketing Research, 51(1), 27-39.

Edlund, J. E., \& Sagarin, B. J. (2014). The Mate Value Scale. Personality and Individual Differences, 64, 72-77.

Egid, K., \& Brown, J. L. (1989). The major histocompatibility complex and female mating preferences in mice. Animal Behaviour, 38(3), 548-549.

Faul, F., Erdfelder, E., Lang, A.-G., \& Buchner, A. (2007). G* Power 3: a flexible statistical power analysis program for the social, behavioral, and biomedical sciences. Behavior Research Methods, 39(2), 175191.

Faulkner, J., Schaller, M., Park, J. H., \& Duncan, L. A. (2004). Evolved disease-avoidance mechanisms and contemporary xenophobic attitudes. Group Processes \& Intergroup Relations, 7(4), 333-353.

Ferdenzi, C., Schaal, B., \& Roberts, S. C. (2009). Human axillary odor: are there side-related perceptual differences? Chemical Senses, 34(7), 565-571.

Gangestad, S. W., Haselton, M. G., Welling, L. L. M., Gildersleeve, K., Pillsworth, E. G., Burriss, R. P., et al. (2015). How valid are assessments of conception probability in ovulatory cycle research? Evaluations, recommendations, and theoretical implications. Evolution and Human Behavior [in press].

Gardner, A., \& West, S. A. (2014). Inclusive fitness: 50 years on. Philosophical Transactions of the Royal Society B: Biological Sciences, 369(1642), 20130356. doi:10.1098/rstb.2013.0356.

Gomes, C., \& McCullough, M. E. (2015). The effects of implicit religious primes on dictator game allocations: a preregistered replication experiment. Journal of experimental psychology: General [Advanced online publication], doi: 10.1037/xge0000027.

Hamilton, W. D., Axelrod, R., \& Tanese, R. (1990). Sexual reproduction as an adaptation to resist parasites (a review). Proceedings of the National Academy of Sciences, 87(9), 3566-3573.

Harris, C., Coburn, N., Rohrer, D., \& Pashler, H. (2012). Two failures to replicate high-performance-goal priming effects. PloS One, 8(8), e72467-e72467.

Havlíček, J., \& Roberts, S. C. (2009). MHC-correlated mate choice in humans: a review. Psychoneuroendocrinology, 34(4), 497-512.

Havlíček, J., Dvořáková, R., Bartoš, L., \& Flegr, J. (2006). Nonadvertized does not mean concealed: body odour changes across the human menstrual cycle. Ethology, 112(1), 81-90.

Havlíček, J., Lenochová, P., Oberzaucher, E., Grammer, K., \& Roberts, S. C. (2011). Does length of sampling affect quality of body odor samples? Chemosensory Perception, 4(4), 186-194.

Huang, J. Y., Sedlovskaya, A., Ackerman, J. M., \& Bargh, J. A. (2011). Immunizing against prejudice effects of disease protection on attitudes toward out-groups. Psychological Science, 22(12), 15501556.

Hughes, A. L., \& Hughes, M. K. (1995). Natural selection on the peptidebinding regions of major histocompatibility complex molecules. Immunogenetics, 42(4), 233-243. 
Isles, A. R., Baum, M. J., Ma, D., Keverne, E. B., \& Allen, N. D. (2001). Genetic imprinting: urinary odour preferences in mice. Nature, 409(6822), 783-784.

Jöchle, W. (1973). Coitus-induced ovulation. Contraception, 7(6), $523-$ 564.

Kenrick, D. T., Sadalla, E. K., Groth, G., \& Trost, M. R. (1990). Evolution, traits, and the stages of human courtship: qualifying the parental investment model. Journal of Personality, 58(1), 97-116.

Kwak, J., Willse, A., Preti, G., Yamazaki, K., \& Beauchamp, G. K. (2010). In search of the chemical basis for MHC odour types. Proceedings of the Royal Society of London B: Biological Sciences, 277(1693), 2417-2425.

Lenochová, P., Roberts, S. C., \& Havlíček, J. (2009). Methods of human body odor sampling: the effect of freezing. Chemical Senses, 34(2), 127-138.

Loehle, C. (1995). Social barriers to pathogen transmission in wild animal populations. Ecology, 76, 326-335.

Lundström, J. N., Boyle, J. A., Zatorre, R. J., \& Jones-Gotman, M. (2008). Functional neuronal processing of body odors differs from that of similar common odors. Cerebral Cortex, 18(6), 1466-1474.

Maner, J. K., \& McNulty, J. K. (2013). Attunement to the fertility status of same-sex rivals: women's testosterone responses to olfactory ovulation cues. Evolution and Human Behavior, 34(6), 412-418.

Marxer-Tobler, E., \& Pineda, J. (2012). Neuroanthropology: olfactory recognition of the self/non-self by the ancestral MHC. International Journal of Biology, 4(4), 1-10.

McNeill, W. H. (1976). Plagues and peoples: a natural history of infectious diseases. New York, NY: Anchor.

Murray, D. R., Jones, D. N., \& Schaller, M. (2013). Perceived threat of infectious disease and its implications for sexual attitudes. Personality and Individual Differences, 54(1), 103-108.

Navarrete, C. D., \& Fessler, D. M. (2006). Disease avoidance and ethnocentrism: the effects of disease vulnerability and disgust sensitivity on intergroup attitudes. Evolution and Human Behavior, 27(4), 270282.

Navarrete, C. D., Kurzban, R., Fessler, D. M., \& Kirkpatrick, L. A. (2004). Anxiety and intergroup bias: terror management or coalitional psychology? Group Processes \& Intergroup Relations, 7(4), 370-397.

Navarrete, C. D., Fessler, D. M., \& Eng, S. J. (2007). Elevated ethnocentrism in the first trimester of pregnancy. Evolution and Human Behavior, 28(1), 60-65.

Newell, B. R., \& Shanks, D. R. (2014a). Prime numbers: anchoring and its implications for theories of behaviour priming. Social Cognition, $32,1-11$

Newell, B. R., \& Shanks, D. R. (2014b). Unconscious influences on decision making: a critical review. Behavioral and Brain Sciences, $37(1), 1-19$.

Park, J. H., Schaller, M., \& Crandall, C. S. (2007). Pathogen-avoidance mechanisms and the stigmatization of obese people. Evolution and Human Behavior, 28(6), 410-414.

Pashler, H., Coburn, N., \& Harris, C. R. (2012). Priming of social distance? Failure to replicate effects on social and food judgements. PloS One, 7(8), e42510.

Pashler, H., Rohrer, D., \& Harris, C. R. (2013). Can the goal of honesty be primed? Journal of Experimental Social Psychology, 49(6), 959964

Penn, D. J., \& Frommen, J. G. (2010). Kin recognition: an overview of conceptual issues, mechanisms and evolutionary theory. In P. Kappler (Ed.), Animal behaviour: evolution and mechanisms (pp. 55-85). Berlin, Germany: Springer.

Porter, R. H., \& Moore, J. D. (1981). Human kin recognition by olfactory cues. Physiology \& Behavior, 27(3), 493-495.

Pratto, F., Sidanius, J., Stallworth, L. M., \& Malle, B. F. (1994). Social dominance orientation: a personality variable predicting social and political attitudes. Journal of Personality and Social Psychology, 67(4), 741-763.

Prokop, P., Fančovičová, J., \& Fedor, P. (2010a). Health is associated with antiparasite behavior and fear of disease-relevant animals in humans. Ecological Psychology, 22(3), 222-237.

Prokop, P., Usak, M., \& Fančovičová, J. (2010b). Risk of parasite transmission influences perceived vulnerability to disease and perceived danger of disease-relevant animals. Behavioural Processes, 85(1), $52-57$.

Roberts, S. C., Gosling, L. M., Carter, V., \& Petrie, M. (2008). MHCcorrelated odour preferences in humans and the use of oral contraceptives. Proceedings of the Royal Society of London B: Biological Sciences, 275(1652), 2715-2722.

Schaller, M. (2011). The behavioural immune system and the psychology of human sociality. Philosophical Transactions of the Royal Society, B: Biological Sciences, 366(1583), 3418-3426.

Schaller, M., \& Murray, D. R. (2008). Pathogens, personality, and culture: disease prevalence predicts worldwide variability in sociosexuality, extraversion, and openness to experience. Journal of Personality and Social Psychology, 95(1), 212-221.

Schaller, M., \& Neuberg, S. L. (2008). Intergroup prejudices and intergroup conflicts. In C. Crawford \& D. L. Krebs (Eds.), Foundations of evolutionary psychology (pp. 399-412). Mahwah, NJ: Erlbaum.

Schaller, M., \& Park, J. H. (2011). The behavioral immune system (and why it matters). Current Directions in Psychological Science, 20(2), 99-103.

Schaller, M., Miller, G. E., Gervais, W. M., Yager, S., \& Chen, E. (2010). Mere visual perception of other people's disease symptoms facilitates a more aggressive immune response. Psychological Science, 21(5), 649-652.

Shanks, D. R., Vadillo, M. A., Riedel, B., Clymo, A., Govind, S., Hickin, N., et al. (2015). Romance, risk, and replication: can consumer choices and risk-taking be primed by mating motives? Journal of Experimental Psychology: General [Advanced online publication], doi: $10.1037 / \mathrm{xge} 0000116$.

Shariff, A. F., Willard, A. K., Andersen, T., \& Norenzayan, A. (2015). Religious priming: a meta-analysis with a focus on prosociality. Personality and Social Psychology Review, [Advanced online publication], doi: 10.1037/xge0000116.

Sheldon, B. C., \& Verhulst, S. (1996). Ecological immunology: costly parasite defences and trade-offs in evolutionary ecology. Trends in Ecology \& Evolution, 11(8), 317-321.

Sherman, P. W., \& Holmes, W. G. (1985). Kin recognition: issues and evidence. In B. Hölldobler \& M. Lindauer (Eds.), Experimental behavioral ecology and sociobiology (pp. 437-460). Stuttgart: Gustav Fischer Verlag.

Singh, P. B. (2001). Chemosensation and genetic individuality. Reproduction, 121(4), 529-539.

Sugiyama, L. S. (2004). Illness, injury, and disability among Shiwiar forager-horticulturalists: implications of health-risk buffering for the evolution of human life history. American Journal of Physical Anthropology, 123(4), 371-389.

Thornhill, R., \& Fincher, C. L. (2014). The parasite-stress theory of values and sociality: infectious disease, history and human values worldwide. New York, NY: Springer.

Thornhill, R., \& Fincher, C. L. (2015). The parasite-stress theory of sociality and the behavioral immune system. In V. Zeigler-Hill, L. L. M. Welling, \& T. K. Shackelford (Eds.), Evolutionary perspectives on social psychology (pp. 419-437). New York, NY: Springer.

Trivers, R. (1985). Social evolution. Menlo Park, CA: Benjamin/ Cummings Menlo Park, CA.

Vaillancourt, T., \& Sharma, A. (2011). Intolerance of sexy peers: intrasexual competition among women. Aggressive Behavior, 37(6), 569-577.

Waldman, B., Frumhoff, P. C., \& Sherman, P. W. (1988). Problems of kin recognition. Trends in Ecology \& Evolution, 3(1), 8-13. 
Wedekind, C., Seebeck, T., Bettens, F., \& Paepke, A. J. (1995). MHCdependent mate preferences in humans. Proceedings of the Royal Society of London B: Biological Sciences, 260(1359), 245-249.

Weisfeld, G. E., Czilli, T., Phillips, K. A., Gall, J. A., \& Lichtman, C. M. (2003). Possible olfaction-based mechanisms in human kin recognition and inbreeding avoidance. Journal of Experimental Child Psychology, 85(3), 279-295.

Wilcox, A. J., Dunson, D. B., Weinberg, C. R., Trussell, J., \& Baird, D. D. (2001). Likelihood of conception with a single act of intercourse: providing benchmark rates for assessment of post-coital contraceptives. Contraception, 63(4), 211-215.

Wu, B. P., \& Chang, L. (2012). The social impact of pathogen threat: how disease salience influences conformity. Personality and Individual Differences, 53(1), 50-54.

Young, S. G., Sacco, D. F., \& Hugenberg, K. (2011). Vulnerability to disease is associated with a domain-specific preference for symmetrical faces relative to symmetrical non-face stimuli. European Journal of Social Psychology, 41(5), 558-563. 